Payments for Ecosystem Services (PES)

A practical guide to assessing the feasibility of PES projects

Emily Fripp 



\section{Payments for Ecosystem Services (PES)}

A practical guide to assessing the feasibility of PES projects

Emily Fripp

Efeca 
(C) 2014 Center for International Forestry Research

Content in this publication is licensed under a Creative Commons Attribution 4.0 International (CC BY 4.0), http://creativecommons.org/licenses/by/4.0/

ISBN 978-602-1504-57-4

Fripp E. 2014. Payments for Ecosystem Services (PES): A practical guide to assessing the feasibility of PES projects. Bogor, Indonesia: CIFOR.

Cover photo by Nick Jewell

Fisherman in Danau Sentarum

\author{
CIFOR \\ Jl. CIFOR, Situ Gede \\ Bogor Barat 16115 \\ Indonesia \\ $\mathrm{T}+62(251) 8622-622$ \\ $\mathrm{F}+62(251) 8622-100$ \\ Ecifor@cgiar.org
}

\title{
cifor.org
}

We would like to thank all donors who supported this research through their contributions to the CGIAR Fund. For a list of Fund donors please see: https://www.cgiarfund.org/FundDonors

Any views expressed in this publication are those of the authors. They do not necessarily represent the views of CIFOR, the editors, the authors' institutions, the financial sponsors or the reviewers. 


\section{Contents}

Preface

Introduction

Aim of this guide

Users of this guide

What is PES?

Introducing payments for ecosystem services (PES) 1

What constitutes PES?

Requirements for PES

Financing for a PES scheme

Consideration of the costs

Transaction costs

Payment mechanisms for PES schemes

Scale of PES schemes

Conclusion

$\begin{array}{ll}\text { Practical steps to assess the feasibility of PES: The 10-step guide } & 7\end{array}$

$\begin{array}{ll}\text { Practical steps to assess the feasibility of PES } & 7\end{array}$

A. The ecosystem service: Steps 1 and 2

Step 1: Identify the ecosystem service 9

$\begin{array}{ll}\text { Step 2: Set clear boundaries } & 10\end{array}$

B. Actors and market access: Steps 3 and 4

Step 3a: Identify the seller(s) 13

Step 3b: Identify the buyer(s) 13

Step 4: Identify the market $\quad 14$

C. Governance and institutional systems: Steps 5 and $6 \quad 17$

Step 5: Determine governance of the ecosystem service $\quad 17$

$\begin{array}{ll}\text { Step 6: Identify institutional and administrative functions/frameworks } & 18\end{array}$

D. Baseline data: Steps 7 and 8

Step 7: Establish and compare business-as-usual and project scenarios 21

Step 8: Collect biophysical data $\quad 22$

E. Credibility, assurance and sustainability: Steps 9 and 10

Step 9: Set requirements for measuring, reporting and verification (MRV) 23

Step 10: Develop pro-poor benefit-sharing mechanisms 24 


\section{Preface}

The report was produced by Emily Fripp, an economist at Efeca, as part of the CoLUPSIA project. The overall objective of the CoLUPSIA project is to avert deforestation and environmental degradation. The project purpose is to establish collaborative and equitable land-use planning and natural resource management through the design and testing of new institutional arrangements, environmental policies and pro-poor financing instruments with the aim of achieving more secure land tenure and commodity rights.

This PES guide, A practical guide to assess the feasibility of PES projects, was developed as part of Expected Result 4: Specific pilot activities supporting propoor financing mechanisms for forest conservation and sustainable management evaluated and begun. This guide seeks to support practical assessments of the potential for PES in CoLUPSIA project sites, identifying the feasibility and the next steps necessary for the effective development of PES. Two district papers assessing the feasibility of PES were produced based on this guide. 


\section{Introduction}

One of the aims of the CoLUPSIA project is to explore options for establishing payments for ecosystem services (PES) within the two districts where the project is working: Seram and Kapuas Hulu. These guidelines were prepared to support the CoLUPSIA team in completing this assessment and have since been revised to incorporate some findings from the field assessments.

For most new PES schemes, the ecosystem service to be paid for has already been identified. Best practice guides, such as that developed by the UK Department for Environment, Food and Rural Affairs (Defra), provide extensive guidance on how to design and implement a PES scheme. However, for the CoLUPSIA project, the purpose of the feasibility assessments was to determine the potential for a PES project and the actions necessary to establish the project. This guide was developed to support that process.

\section{Aim of this guide}

This guide aims to facilitate the identification and implementation of PES at any level from community to district to national to international. The guidelines take the user through 10 practical steps to identify and assess the feasibility of establishing PES projects. In practice, this assessment is the first step in the overall development and implementation of PES projects. Where possible, the guide includes practical examples, tools and further information to facilitate this process. For full implementation of a PES scheme, alternative guides are available, such as Defra's Payments for Ecosystem Services: A Best Practice Guide.

\section{Users of this guide}

This guide is written for field practitioners in the preliminary stages of establishing a PES scheme. It seeks to support those working in countries that have complex governance structures, multiple ecosystem services and limited administrative capacity.

This tool will also prove useful for other development programs and projects that seek to explore the potential for a PES scheme and assess what factors should be considered when developing such a scheme, donor program or project. 



\section{What is PES?}

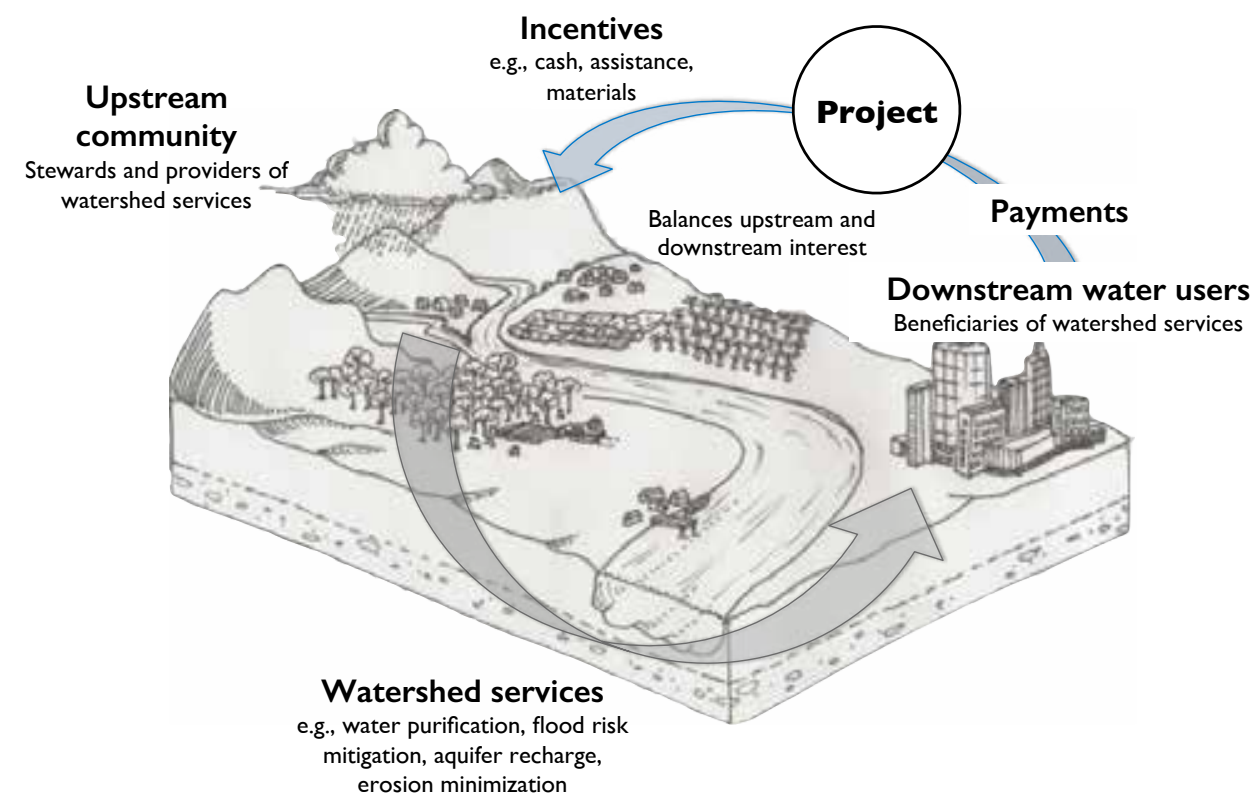

Figure 1. An example of how PES works in watersheds.

Source: adapted from Smith et al. 2013

\section{Introducing payments for ecosystem services (PES)}

The term "ecosystem services" refers to the diverse benefits that are derived from the natural environment. Examples include the supply of food, water and timber (provisioning services); the regulation of air quality, climate and flood risk (regulating services); opportunities for recreation, tourism and education (cultural services); and essential underlying functions such as soil formation and nutrient cycling (supporting services). ${ }^{1}$

Payments for ecosystem services (PES) occur when the beneficiaries or users of an ecosystem service make payments to the providers of that service. In practice, this may take the form of a series of payments in return for receiving a flow of benefits or ecosystem services. The basic idea is that whoever provides a service should be paid for doing so (Figure 1).

The last 10 to 15 years has seen a rapid proliferation of PES schemes. The Kyoto Protocol and the introduction of REDD+ have brought PES to international

1 Smith S, Rowcroft P, Everard M, Couldrick L, Reed M, Rogers H, Quick T, Eves C and White C. 2013. Payments for Ecosystem Services: A Best Practice Guide. London: Defra. 
forums. Several mechanisms for PES are available. Some mechanisms are well developed, such as where urban areas pay for watershed protection in upland areas (e.g. New York; see Box 1) and carbon credits are bought and sold on voluntary carbon markets. Other schemes, such as payments for biodiversity, are more exploratory.

\section{What constitutes PES?}

According to Savy and Turpie (2004), ${ }^{2}$ a PES scheme can develop in one of two ways: either at least one set of stakeholders recognizes a noticeable depletion in resources, leading to true demand, or a particular aim is identified, usually in relation to protection or management of national resources and a PES system is introduced to create a market for the service.

Typically, but not always, PES options or programs are based on the following ecosystem services or bundles: ${ }^{3}$

1. carbon sequestration and storage

2. biodiversity protection/bundled services (highly efficient but very difficult to organize and maintain $)^{4}$

3. watershed protection (often occurs when at least one stakeholder recognizes the need for resource protection and a willingness to pay suppliers ensues, often using intermediaries such as government or nongovernmental organizations (NGOs) to channel payments from users and suppliers ${ }^{5}$

4. landscape beauty (for example, for ecotourism).

\section{Requirements for PES}

For all PES, the buyer must be identified, the market conditions understood (including any conditionalities) and the service provider legally and institutionally recognized. A widely quoted definition of a PES is that it is:

1. a voluntary transaction where

2. a well-defined ecosystem service (or a land use likely to secure that service)

3. is "bought" by a (minimum of one) ecosystem service buyer

4. from a (minimum of one) ecosystem service provider; if and only if

5. the service provider secures ecosystem service provision (conditionality).

2 Savy CE and Turpie JK. 2004. Payments for Ecosystem Services: A Review of Existing Programmes and Payment Systems - Appendix. Rhodes Gift, South Africa: Anchor Environmental Consultants CC.

3 Wunder S. 2006. Are direct payments for environmental services spelling doom for sustainable forest management in the tropics? Ecology and Society 11(2):23. www.ecologyandsociety.org/vol11/iss2/art23/ main.html

4 Landell-Mills N and Porras IT. 2002. Silver Bullet or Fools' Gold? A Global Review of Markets for Forest Environmental Services and their Impacts on the Poor. Instruments for Sustainable Private Sector Forestry Series. London: International Institute for Environment and Development.

5 Landell-Mills N and Porras IT. 2002. 
The Defra PES Best Practice Guide draws on this definition to identify seven key principles, which ideally underpin any PES scheme:

1. Voluntary: Stakeholders enter into PES agreements on a voluntary basis.

2. Beneficiary pays: Payments are made by the beneficiaries of ecosystem services (individuals, communities and businesses or governments acting on behalf of various parties). This requires that there be a clear demand for the service(s) in question, and its provision is financially valuable to one or more potential buyers.

3. Direct payment: Payments are made directly to ecosystem service providers (in practice, often via an intermediary or broker).

4. Additionality: Payments are made for actions over and above those that land or resource managers would generally be expected to undertake (note that precisely what constitutes "additionality" will vary from case to case but the actions paid for must at the very least go beyond regulatory compliance). That is, specific land or resource management actions must have the potential to increase the supply of a particular service (or services).

5. Conditionality: Payments are dependent on the delivery of ecosystem service benefits. In practice, however, payments are more often based on the implementation of management practices that the contracting parties agree are likely to give rise to these benefits.

6. Ensuring permanence: Management interventions paid for by beneficiaries should not be readily reversible, thus ensuring continued service provision.

7. Avoiding leakage: PES schemes should be set up to avoid leakage, leakage referring to the situation where securing an ecosystem service in one location leads to the loss or degradation of ecosystem services elsewhere.

Put simply, there are three components of successful PES: demand, supply and the appropriate transaction infrastructure (i.e. marketplace). In all cases, a robust scientific baseline and supporting information are basic requirements.

Savy and Turpie also identified three enabling factors for PES to succeed:

1. valuation (quantification of the impact and economic valuation)

2. legal and institutional frameworks

3. organization of stakeholders.

These are particularly relevant when working in a complex environment (complex ecosystem services within a highly political economy with many actors and differing agendas). In Indonesia, for example, the legal and institutional framework is often not well defined, and land tenure is often unclear or insecure.

\section{Financing for a PES scheme}

The Defra PES Best Practice Guide defines three broad types of payment for PES schemes:

- public payment schemes through which the government pays land or resource managers to enhance ecosystem services on behalf of the wider public 
- $\quad$ private payment schemes, or self-organized private deals, in which beneficiaries of ecosystem services contract directly with service providers

- public-private payment schemes that draw on both government and private funds to pay land or other resource managers for the delivery of ecosystem services.

As key principle 6 (ensuring permanence) states, it is important that the financing structure of any PES is both sustainable and sufficient. This ensures that the incentive to provide the ecosystem service remains even in the face of continued competing land uses. For example, a relatively small incentive that compensates rubber agroforestry farmers for the opportunity costs of not converting their lands to oil palm monoculture can make more environmentally friendly land-use systems the most attractive for farmers. This may lead to substantial gains (or avoid substantial losses of) environmental services for a moderate cost. The problem, however, is that the opportunity for conversion will remain and recurrent rewards may be needed for the service to be continually provided.

For PES to work, it must provide a "win-win" opportunity for both the supplier and the buyers of the service. The buyer covers the cost of provision, which must be (1) lower than any alternative method by which the buyer might secure the same service, and (2) sufficient to ensure that the alternatives, for example conversion of land to an alternative use, are less economically attractive (Figure 2).

\section{Consideration of the costs}

No PES scheme can succeed without a robust and credible business case and an accurate estimate of costs, including transaction costs. As shown in Figure 2, the payment must be high enough to fully cover all costs, incentivize the seller to provide the service over the long term and ensure income from alternative land uses is offset.

When establishing the business case for PES, two categories of costs must be considered:

- Short-term design and capacity-building costs: These costs may require upfront finance for research, data collection for the baseline, stakeholder engagement and contract preparation. Front-loaded payments may be required to cover sellers' upfront costs.

- Longer-term implementation costs: These costs cover the payments necessary to generate additional ecosystem service provision and to cover transaction costs and all costs of measuring, reporting and verification (MRV). 
Conversion to

pasture
Forest

conservation conservation with service payment(s)

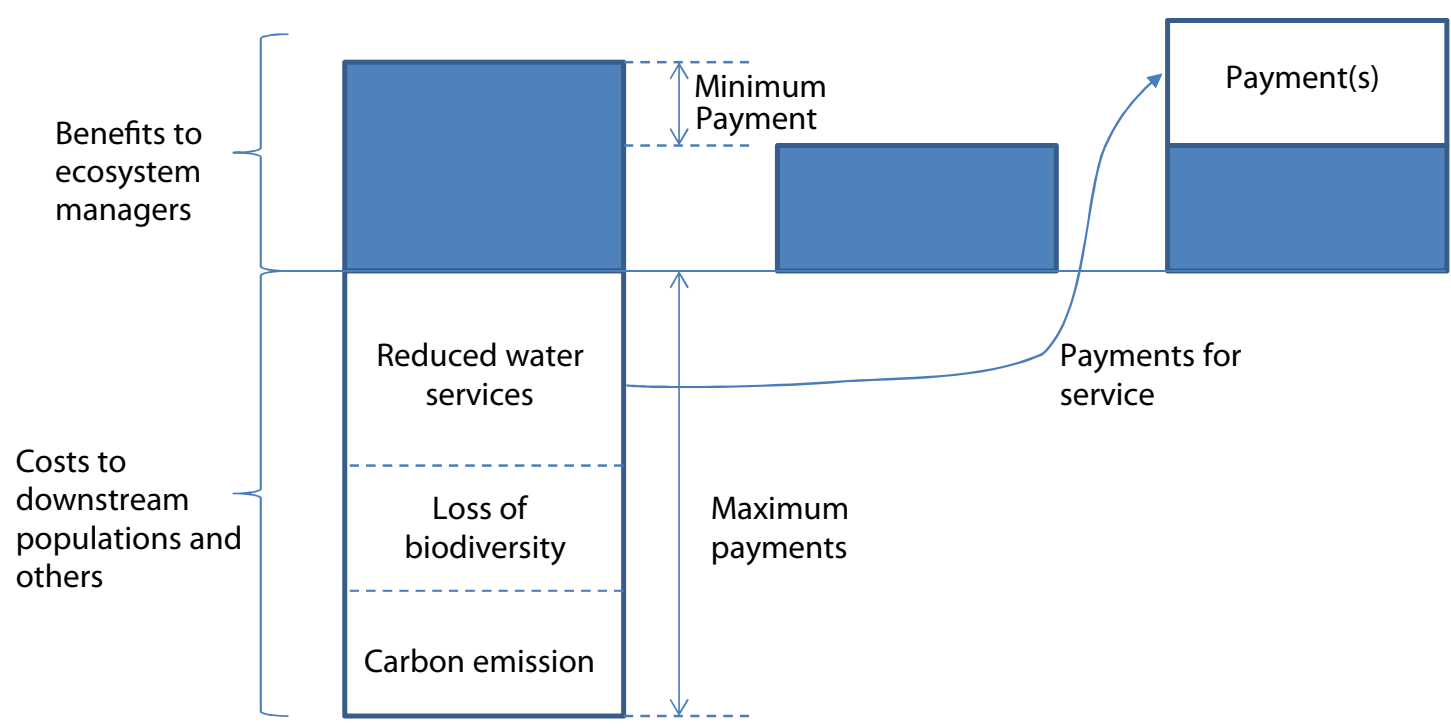

Figure 2. Example of structure for payments under PES.

Source: Engel S, Pagiola S and Wunder S. 2008. Designing payments for environmental services in theory and practice: An overview of the issues. Ecological Economics 65:663-74.

\section{Transaction costs ${ }^{6}$}

Transaction costs, defined as all costs associated with buying and selling in a market, are critical to the success of a working PES scheme. Transaction costs include time taken to agree on the nature, extent and timing of the payments or in-kind transfers; drawing up contracts; and monitoring the outcomes of the agreement for all parties. The level of transaction costs can "make or break the market." For example, there is growing evidence that transaction costs within PES mechanisms might be higher than anticipated by PES developers, which may contribute to the high frequency of project failure. ${ }^{7}$

\section{Payment mechanisms for PES schemes}

There are two main mechanisms for PES: ${ }^{8}$

- Performance-based payments: These are payments made on the basis of the actual provision of the ecosystem service. For example, payments are made for a certain amount of carbon sequestration, a measured increase in biodiversity,

6 Meijaard E, Sheil D, Guariguata MR, Nasi R, Sunderland T and Putzel L. 2011. Ecosystem Services Certification: Opportunities and Constraints. CIFOR Occasional Paper 66. Bogor, Indonesia: CIFOR.

7 Meijaard et al. 2011.

8 Smith et al. 2013. 
or an improvement in water quality. Ideally, performance-based payments would form the basis of all PES schemes.

- Input-based payments: These are payments made on the basis of certain land or resource management practices being implemented, for example the creation of buffer strips along watercourses. These types of payments will eventuate only if buyers are willing to accept that specified inputs/activities will result in the provision of the desired ecosystem service.

\section{Scale of PES schemes}

PES schemes can be developed at a range of spatial scales, including the following:

- International: One example of an international mechanism is Reducing Emissions from Deforestation and forest Degradation (REDD+), whereby developing countries that are willing and able to reduce emissions from forest degradation and loss are paid by developed countries for doing so.

- National: An example is the Environmental Stewardship Programme in the UK, a government-financed scheme under which about GBP 400 million a year is paid to farmers and land managers on behalf of the public in return for more environmentally sensitive farming.

- Catchment: For example, downstream water users pay for appropriate management of the watershed or upstream land. These schemes tend to be privately financed, for example where a water utility pays upstream land managers on behalf of its customers to implement certain measures designed to stabilize or improve water quality.

- Local/neighborhood: For example, a scheme whereby residents collectively fund the efforts of a warden or environmental organization to manage local green spaces for their biodiversity, landscape and recreational values.

\section{Conclusion}

There are a number of options for what constitutes PES, how it should be established and the most appropriate means of financing it. In all cases, an appropriate ecosystem service must be identified, based on solid scientific data, but a payment for the ecosystem service can only be established if the value of this service is recognized by both a buyer and a seller and the appropriate transaction infrastructure (marketplace) is established.

This practical guide to identifying and assessing the feasibility of PES is based on 10 steps that lead the user through the process of identifying the service, the buyer, the seller and the market.

9 Smith et al. 2013. 


\section{Practical steps to assess the feasibility of PES: The 10-step guide}

\section{Practical steps to assess the feasibility of PES}

This PES guide focuses on identifying and assessing the feasibility of PES schemes, drawing on lessons learned from the CoLUPSIA project. The starting point is assessing the potential of PES, rather than establishing PES.

This feasibility guide is relevant primarily to users in similar circumstances to those of CoLUPSIA: they want to establish a PES scheme in an area rich in ecosystem services but that have many complex challenges, including unclear ownership and rights over the ecosystem services in question, intricate governance structures and various political-economic considerations. This guide can be used by field practitioners wishing to ascertain the feasibility and potential PES options of a particular landscape. Outcomes of this assessment could also be incorporated into land-use planning decisions, if feasible.

In the PES Best Practice Guide (2013) funded by Defra, ${ }^{10}$ identifying the potential for PES in an area is only the first activity in the process of setting up a fully operational PES scheme. The Best Practice Guide also includes Phases 2, 3, 4 and 5 , which set out further activities in preparing and implementing the PES scheme, including negotiating agreements between buyers and sellers, monitoring and evaluation. The scope of the CoLUPSIA guide is activities covered by Phase 1 in the Defra Best Practice Guide (identification of the potential PES scheme). The present guide assesses the feasibility of establishing such a PES scheme and concentrates on aspects in the first two components of the Defra Best Practice Guide:

1. Identify ecosystem service prospects, potential buyers and sellers.

2. Resolve institutional, legal and technical issues.

In practice, identifying the ecosystem services and potential buyers and sellers and then resolving institutional, legal and technical issues can be highly complex, and these stages require significant time and expertise; this is particularly the case in Indonesia. The present guide aims to support users as they work through all the practical issues and considerations required, in 10 steps (Figure 3).

10 Smith et al. 2013. 


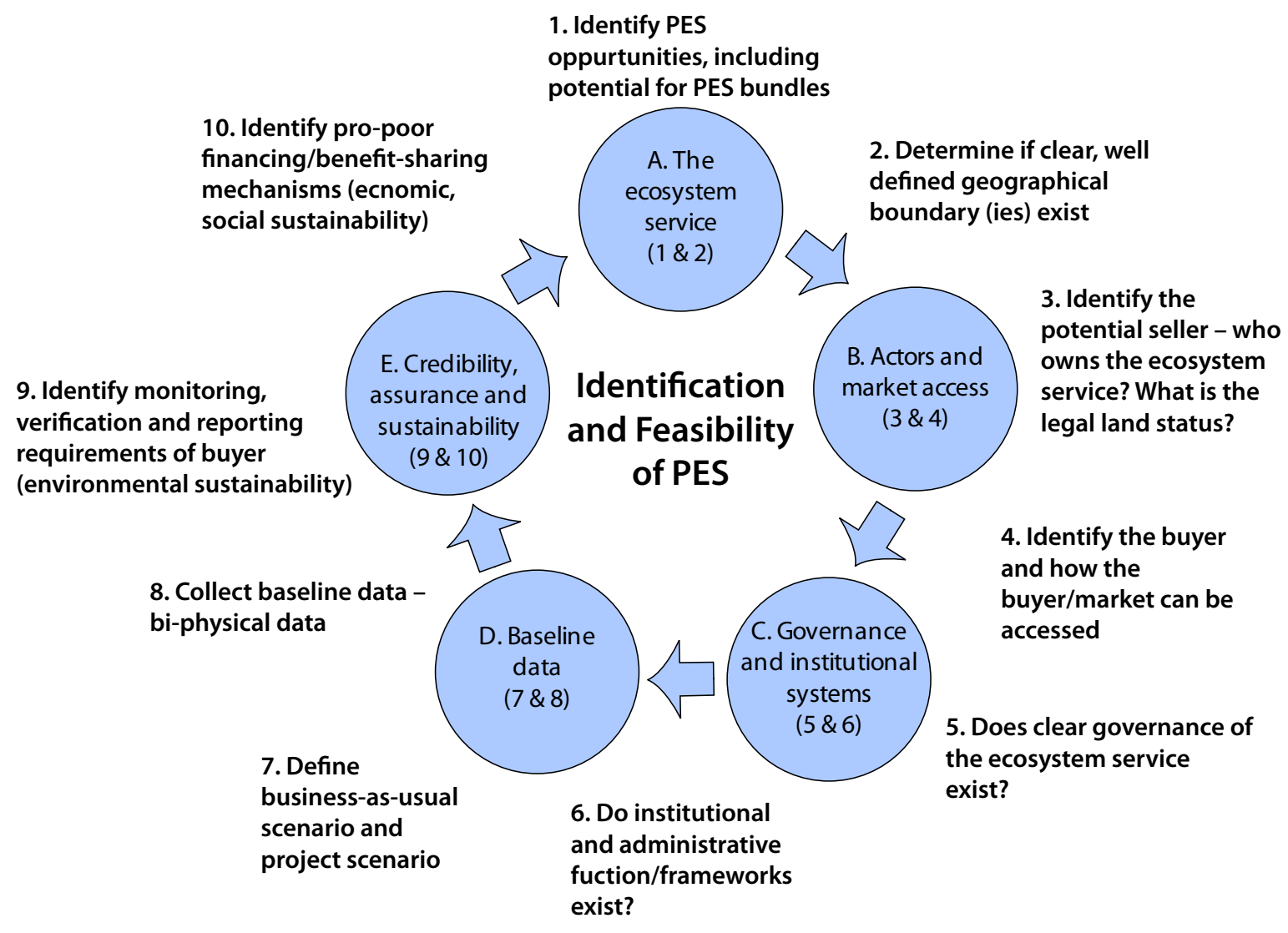

Figure 3. The 10 steps in assessing the feasibility of PES. 


\section{A. The ecosystem service: Steps 1 and 2}

\section{Step 1: Identify the ecosystem service}

\section{What is the ecosystem service that is going to be bought and sold?}

In most cases, it is apparent what ecosystem service is going to be bought and sold. Usually, the emergence of a problem, such as downstream water pollution or demand for carbon credits, drives the establishment of a PES scheme (see Box 1). However, in some cases, such as that of CoLUPSIA (see Box 2) and other

\section{Box 1. Watershed protection in New York, USA}

This long-term watershed protection program serves to provide a source of highquality drinking water for nine million consumers.

The ecosystem service: Improved water quality with the additional benefits of education and awareness programs and ecosystem integrity.

The program was funded by the New York City Department for Environmental Protection at a cost of USD 1.5 billion. The estimated alternative cost was USD 8-10 billion, for water treatment plants and other costs.

Source: http://www.nyc.gov/html/dep/html/watershed_protection/index.shtml

\section{Box 2. Ecosystem services and the CoLUPSIA project}

The two project sites in the CoLUPSIA project, in the districts of Kapuas Hulu and Seram in Indonesia, have extensive natural resources that could provide opportunities for PES, including biodiversity, carbon stocks, watershed and landscape beauty, as well as debt-for-nature swaps (The Nature Conservancy/Kapuas Hulu). The potential of all ecosystem services for PES was assessed.

Pressure for land is increasing in both areas, because of economic development, often for the production of commodities such as palm oil, and population growth. This is putting pressure on natural resources and creating a need for alternative means of development. It has become imperative that the full value of these services be appreciated and accounted for in land-use decisions. 
development projects or programs, the objective may be to assess the potential of ecosystem services for inclusion in a PES scheme. These assessments will require exploring, at community, district, provincial or even national level, whether the available ecosystem services are suitable for PES.

To identify the service to be sold, the following questions should be considered:

- Well-identified issue or threat to the ecosystem: Is there a well-identified issue (poor-quality drinking water) or service (carbon sequestration) that someone is willing to pay for and someone is willing to sell? Is there a threat to the ecosystem service from alternative land use, driven by the need for economic development, population growth or some other pressure? For example, is there a noticeable change in resources (water quality, forest cover, biodiversity, carbon emissions) that is recognized by at least one set of stakeholders, who are willing to pay to rectify/address the situation? There must be a clear cause and effect, where buyers are confident that the ecosystem service purchased will provide the desired benefit.

- Additionality: Does the service to be bought/sold provide an additional benefit to the buyer (provision of carbon credits) and/or will there be a change in behavior of the supplier (changing their agricultural practices)? The change in behavior by either buyer or seller will instigate the market mechanism for such payments.

\section{Bundled ecosystem services and leakage}

Ecosystems provide a wide range of services. The ecological processes that interact to produce these services are highly complex, so it is often difficult - and possibly misleading - to isolate and pay for just one ecosystem service without simultaneously considering other services. In some situations, focusing on a single ecosystem service may also mislead policy. For example, a well-maintained lake ecosystem generates multiple benefits, including clean drinking water, food production and recreation. Another consideration is whether a bundle of ecosystem services should be used as a PES scheme, which may help both to avoid the conflicts and potential trade-offs between land-use management options and to combine the benefits.

\section{Step 2: Set clear boundaries}

\section{Are there well-defined and clear geographic boundaries for the service?}

A fundamental requirement for any PES scheme is the establishment of clear, well-defined geographic boundaries. In practice, this means that if, for example, clean water is provided to a downstream user, the water catchment must be clearly defined, with no risk of leakage. There must be a clear link between the cause and effect of any change in behavior, as shown in Box 3. 


\section{Box 3. The example of Vittel, France}

Vittel was aware that its water source was at risk from nitrate contamination because of agricultural intensification in the area. The ecosystem service identified was improved water quality. Vittel purchased 1500 hectares of land around its water springs and paid farmers to farm more sustainably and improve facilities. It cost them USD 9 million. The geographic boundaries of the watershed were clearly defined and brought under control to reduce pollution, thus safeguarding Vittel's product, drinking water.

Source: http://pubs.iied.org/

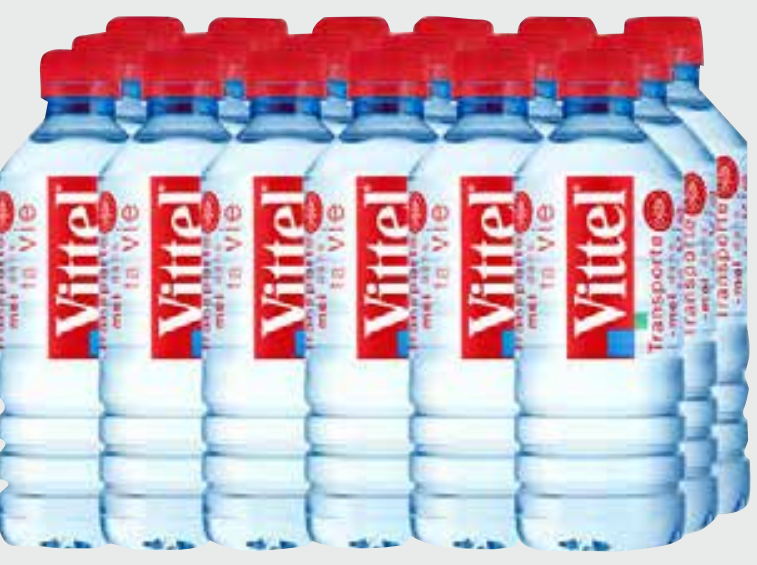
G00388.html

\section{Box 4. Challenges for a WWF PES project in Kapuas Hulu, West Kalimantan}

The CoLUPSIA project is working near the Medalam River, which is severely affected by sedimentation caused by agroforestry and agricultural practices, coupled with extensive gold dredging and timber harvesting. The Medalam River joins the Kapuas and Sibau Rivers before flowing down to Putussibau, the district capital. The water company in Putussibau recognizes the problems of increased water sedimentation and poor quality and is willing to consider options, including PES, to resolve the issue.

However, the primary focus of the project is on improving agricultural practices in the Medalam River area. The project is working to improve agroforestry practices, enrich gardens, monitor hydrology and build capacity for activities such as rubber production. In 2007, a baseline study on water quality was completed and, in 2009, monitoring of water quality was introduced.

In its current form, the project does not meet all the requirements for a PES scheme. Although the water company is supportive and interested in being engaged, a clear and robust cause and effect between improved agricultural practices in the Medalam River area and the water sedimentation downstream at Putussibau is lacking. Too many other factors are influencing the water quality, including unclear geographic boundaries for the ecosystem service provision with leakage from other watersheds and other activities. 
A watershed may have more than one source of sedimentation, such as different users or subsidiary watersheds feeding into the ecosystem and thus affecting the ecosystem service to be supplied. For example, in the case of Kapuas Hulu (Box 4), a downstream water company in Putussibau (the main town in the district) sources its water at a point where three rivers join. The water quality is declining for several reasons, which makes it impossible to identify a direct link (cause and effect) between the changes in behavior of, for example, farmers around one river and any change in the ecosystem service (clean water) bought by the water company downstream. 


\section{B. Actors and market access: Steps 3 and 4}

\section{Step 3a: Identify the seller(s)}

\section{Who owns the ecosystem service? Who is legally entitled to sell the ecosystem service?}

Step 3a considers the need to clearly identify who owns the service and therefore who is eligible to sell the service. This may seem like an obvious point, but knowing who can rightfully sell the ecosystem service is not always straightforward.

For example, when dealing with sales of carbon credits from a forest area, the seller may need to "own" the carbon stocks in order to be allowed to sell credits for them. This may require owning the trees, the land on which the trees grow, or both; ownership rules are likely to vary from one country to another. Forested areas may be leased to a community or private company for use, which may or may not include the sale of carbon credits. Ownership must therefore be clearly established.

In some cases, for example the case of forest land in Indonesia, tenure or rights to use or own the land are often unclear and in conflict. The Indonesian state definitions of ownership, use and boundaries may also differ from those of community-based adat (customary) law. Therefore, before establishing PES, land ownership and use rights must be clarified, documented and accepted by all parties. The prospect of generating additional revenue from the sale of ecosystem services could trigger conflicts if the ownership rights are not clearly established.

One way to address this issue is to engage all local parties - communities, district government and private sector, among others - to build trust, dialogue and commitment to the process. Free, prior and informed consent (FPIC), a condition for many certification schemes, provides a useful framework for PES for engaging all local parties and including them in decision making.

If ownership of the ecosystem service cannot be fully clarified, then PES will not be feasible.

\section{Step 3b: Identify the buyer(s)}

Who is going to buy the ecosystem service? Is the buyer known to the seller? Having a buyer is essential. There is no point in investing time and resources in establishing a product or service to sell if there is no buyer or market (or access to 
the market). This may seem obvious, but some programs have begun assessing the technical and biophysical capabilities of the ecosystem service provision, without checking that there is in fact a buyer that is willing to pay for the ecosystem service, and a thus a market.

However, in some cases, the buyer will have identified the service to be bought and sold. For example, a water company may have experienced higher costs because of increased sedimentation of the water. The water company may then approach the upstream farmers to negotiate ways to improve the sedimentation and cover the costs, as in the case of Vittel (Box 3). In other cases, a carbon credit project may be established that links the buyer directly with the seller, as in the case of Fauna \& Flora International (FFI) in Kapuas Hulu (Box 8). In these cases, the buyer is known.

In other cases, the direct buyer is unknown, but access to an intermediary buyer or a market mechanism is still feasible. For example, if the community identifies an opportunity to sell carbon credits, then the buyer may be an international market or a single entity, such as an intermediate company that then sells to the international market. In such cases, the seller has very limited interaction with the buyer and even the market. The price and conditions of sale may be fixed.

For services such as biodiversity protection and landscape beauty, the buyers may initially be unknown to the seller, so it will be necessary to conduct market research and connect to potential buyers, drawing on local knowledge, expertise and networks as a first step.

In all cases, the buyer and the associated market may set conditions that the supplier must meet, in relation to aspects such as quality, monitoring, reporting and verification.

\section{Step 4: Identify the market}

In what market will the ecosystem be sold: international, national, local? How accessible is the market? What are the rules governing the market? How is the price set?

The process of determining how to access the market and set the price involves several considerations. For example, does the price take into account the costs, as is the case for a product? Or does the producer have to accept a price set by the international markets (as in carbon markets) or by an international body (as for a debt-for-nature swap)? Or is the price negotiated according to the buyer's willingness to pay (WTP) for the service and a supplier's willingness to accept (WTA) that price? This is a critical step in establishing and implementing PES. 


\section{4a: Access to the market}

Determining access to the market is a key issue that is often overlooked, or project proponents assume that it will simply happen and leave it until last. However, as for the launch or sale of any product, the market must be researched and, if necessary, the appropriate transaction infrastructure or market mechanisms established. The market must be accessible to both buyer and seller. For example, if a community decides to sell carbon, then the community will need advice on how to access the international carbon market.

\section{Market conditionalities}

In addition, some markets have rules or conditionalities that the buyer and seller must adhere to. For example, those wanting to sell carbon credits must comply with the requirements of the relevant voluntary carbon market, such as the need for verification. For improved water services, parties must agree on how changes will be measured, monitored and reported. The seller and/or buyer may incur additional costs (included in the transaction costs) because of the market rules or conditionalities, such as the costs of voluntary verification of carbon emission reductions.

For some markets, the seller may have to meet MRV requirements. The cost and practicality of fulfilling MRV requirements should be carefully considered when developing the PES scheme, especially when making the business case, to determine whether the proposed payments will cover all costs incurred. Where external auditing is required, as in the case of voluntary carbon markets, costs can be high and the price, which is set in international markets, is volatile. Risks such as these should be carefully considered.

\section{4b: Setting the price to ensure sustainable financing}

The price set has to be satisfactory for both parties. The income that local stakeholders receive must be enough not just to cover the total costs of the project but to exceed them, in order to provide an incentive to stakeholders to refrain from business as usual and ensure permanence of the ecosystem service. Alternatives to providing the ecosystem service must be more expensive for both buyer and seller, thus ensuring that alternative land uses, or business as usual, are seen as inferior options to providing the ecosystem service. Where transaction or initial investment costs are high, proponents may need to look for and secure alternative means of finance (including international donor support; Box 5).

Options for determining the price for an ecosystem service include the following:

- Negotiation: For example, in the case of watershed services, the end beneficiary or the buyer (e.g. the water company) may indicate a price that they would be willing to pay to the supplier of the service (e.g. upstream farmer) for the service (e.g. clean water, improved agricultural practices to reduce sedimentation). This payment is not necessarily cash, but may be payment 
in-kind. Parties would agree on the payment type or amount through a negotiation process.

- Market prices: For example, in the case of carbon credits, the supplier will have very little influence over the market price, as it is set in an international market. By contrast, in the case of certified products, the supplier may be able to influence the price, as long as the buyer is willing to pay for it.

As many ecosystem services are not sold on a market, there is no price that reflects the services' economic value. In some cases, the market price may undervalue the service. The total economic value of an ecosystem service can be assessed using economic valuation techniques. This value can then be used to inform price negotiations. There is an extensive literature on techniques for assessing the economic value of ecosystem services; it is not further discussed here.

\section{Box 5. PES in Costa Rica}

A project in Costa Rica, led by the World Bank, aims to secure long-term sustainability through PES mechanisms. The ecosystem services provided are water regulation, carbon sequestration and biodiversity protection. New sustainable financing mechanisms were created to support the provision of the ecosystem services, including the following:

- a water tariff

- a Conservation Trust Fund

- carbon sequestration

- voluntary markets for biodiversity conservation.

Source: http://www.worldbank.org/projects/P093384/mainstreaming-market-basedinstruments-environmental-management-project?lang=en\&tab=overview

\section{Potential risk: Price sensitivity and market volatility}

Prices may fluctuate for any ecosystem service being sold. In the case of carbon credits, for example, the market price is set internationally and the producer has very little, if any, scope to influence the price; in this case, tightening supply to boost the price would succeed only if the supply were very large, which is highly unlikely for most ecosystem service providers. This means that, if the price falls, the income generated may not cover the cost of service provision. Those selling ecosystem services should consider this risk carefully. This risk should be factored into the financial feasibility of establishing a PES project. 


\section{Governance and institutional systems: Steps 5 and 6}

\section{Step 5: Determine governance of the ecosystem service}

\section{Are the necessary governance arrangements in place?}

It is imperative that governance of the ecosystem service be clear. It is therefore necessary to understand the governance framework in the village, group of villages or landscape - the potential seller(s) — where the ecosystem service will be produced, managed and sold.

In the case of the hamlet of Masihulan (a CoLUPSIA project site) in Seram, for example, the governance system is intricately linked to legal administrative requirements of the village that has administrative control of Masihulan. Where customary governance systems and legal administrative systems are interlinked, the intricacies and complexities must be mapped and understood (see Box 6). The

\section{Box 6. Aspects of governance for consideration}

- Who or what body (the hamlet, village, individual) has the legal right and capacity to govern the PES system?

- What are the governance relationships with other neighboring villages and hamlets?

- Will the sale of an ecosystem service involve more than one hamlet or village? How will the governance framework be established? How will it work in practice?

- In some villages and hamlets, traditional customary governance systems dominate, whereas in others, the formal legal administrative system is more pertinent. What is the case for the site for which PES is being assessed?

- How will the situation be managed if PES is established in one hamlet and not in others or not at the village level? Will the village that administratively oversees the hamlet require payment or compensation of some kind?

- Do traditional and democratic election processes influence governance of natural resources? How are the land and natural resources governed?

- Will PES be established on household, hamlet or village land? What are the implications for resource governance, including income derived from selling the resource? 
mapping should include any procedures that are relevant to PES, such as making decisions and allocating funds.

It is therefore important to thoroughly understand existing governance systems at hamlet, village or landscape level for managing natural resources, as well as to identify governance-related risks associated with establishing PES in one part of the village or hamlet and include ways to mitigate those risks in the PES project plan.

\section{Step 6: Identify institutional and administrative functions/ frameworks}

\section{Are the necessary institutional arrangements in place?}

An institution to handle the sale of the service is necessary, as for any product that is being sold in a market. In this regard, the first step is to identify a suitable institution with clear ownership rights to the ecosystem service. The next consideration is whether institutional and administrative capacity is sufficient.

The "institution" may be a local community group, an individual, a government body or an intermediary body such as a local NGO. It must have adequate administrative and technical capacity to manage and sell the ecosystem service. An important aspect to consider is who will be the staff member or responsible person(s) to liaise on the "production" of the service, identification of the market and buyer, the sale itself, and the disbursement of any revenues received (Box 7). In some cases, a new institution will be required, whereas, in others, an existing institution can be developed or strengthened. For example, a community may have a group for managing resources or coordinating the sale of agricultural commodities

\section{Box 7. Points to consider for capacity building}

As with any business, training in the following may be required.

- Establishing the rules of procedures on how the business (selling the PES) will be managed.

- Who is involved, what are their roles and responsibilities, for example the accountant (finance), the person monitoring the service provision (production and quality control), the person talking to the buyers and agreeing on the price (the sales person).

- Managing the funds/payments: Has a bank account been set up? Who is responsible for managing the funds? How will the funds be disbursed - as individual payments or for community services? Is there an agreement in place?

- Do procedures exist for managing any potential conflict that may arise?

- Is there sufficient capacity and technical know-how to provide the MRV to prove service provision/additionality, to meet the buyer requirements (water quality, carbon offsets, etc.)? 
that could take on the responsibility of managing PES but it is likely to require capacity building and technical support.

In Seram and Kapuas Hulu, villages and hamlets tend to have simple administrative structures in place, primarily to administer village funds from the government. In these cases, the processes often need to be strengthened. However, in some cases, such as the sale of carbon credits under the FFI project in Kapuas Hulu, a new institution is likely necessary (Box 8) to meet legal requirements for selling PES.

\section{Box 8. Ecosystem restoration: Community carbon project working with a private company and Fauna \& Flora International (FFI)}

In 2009, demonstration sites for potential carbon projects on land allocated for "ecosystem restoration" were identified through baseline studies (e.g. biodiversity, carbon, social and economic indicators). The main criterion was that the project be located on deep swamp forest. The Siawan Belida area was selected for ecosystem restoration, which is a form of concession that permits the sale of carbon credits. The ecosystem service identified for sale is carbon sequestration.

The land was originally a forest concession (HPH) with clear boundaries, managed by the company Bumi Riya. The land is now designated as forest conversion land (HPK) and was selected for ecosystem restoration. Some community land lies within the concession boundaries but requires further demarcation. For this reason, participatory mapping of community areas in the HPK and mapping of administrative boundaries are underway. Participatory mapping will help ensure compliance with the FPIC requirements of carbon certification standards. The area includes eight villages from four subdistricts.

A Memorandum of Understanding has been signed between the government, FFI, the community and the private company that will manage the ecosystem restoration concession. To manage the PES scheme, two institutions have been established:

1. a joint institution for the eight villages involved

2. a forest restoration company, PT Wani Hijau Nusontra (PT WHN).

PT WHN was established as a private company, through collaboration between $\mathrm{FFI}$ and BioCarbon (an international company). To meet legal requirements, a new body known as Yoyas Hutan ljou was founded to oversee PT WHN. PT WHN will generate carbon credits according to carbon standards and sell the carbon credits on voluntary markets. At the time of writing, the details of roles, responsibilities and procedures remain to be clarified. However, the main principles are in place: to ensure that community rights are respected and local governance is strengthened.

In establishing this scheme, the main issue has been the underestimation of the importance of (and the time required) achieving appropriate land ownership status 
Box 8. Continue

and concession title. The current status of this PES project is unclear as this area's status will be changed to that of Hutan Lindung (protected area) according to the new land-use plan and will not be eligible for an ecosystem restoration project. Communities are objecting to this proposed change in land status, because the change would mean that the communities would no longer have access to the forest for any use.

In terms of benefit sharing, a government declaration states that all revenues (not profit) from the sale of carbon credits be split as follows:

- $20 \%$ to the communities (shared among the eight villages but details of how the shares will be further divided are yet to be decided).

- $20 \%$ to the government

- $60 \%$ to the private company (PT WHN), to cover all costs of production, including verification.

Source: CoLUPSIA interview with FFI, Putussibau, West Kalimantan, 2012. 


\section{Baseline data: Steps 7 and 8}

\section{Step 7: Establish and compare business-as-usual and project scenarios}

\section{What is the business-as-usual scenario? How is this expected to change as a result of the PES scheme, i.e. what is the additionality?}

Establishing the baseline is a prerequisite for all PES projects, including those for REDD+ or those dealing with carbon sequestration, watershed management or biodiversity protection. The baseline scenario sets out the forecast for what would happen in the absence of the PES scheme. This scenario is then compared to the forecast outcomes of the PES scheme. The additionality, such as enhanced carbon stocks or provision of cleaner water, is the service that is provided and sold to the buyer.

The baseline scenario then provides the basis against which the performance of the PES project will be assessed (measured, reported and verified).

Payments for providing an ecosystem service may be conditional upon performance (performance-based payments), where the implementation of PES results in a desired change in the ecosystem service that would not have happened in the absence of the intervention. This change could be positive, such as an improvement in the ecosystem service, or it could be the prevention of a negative change to the ecosystem service.

By introducing a PES project that involves payments for carbon sequestration, the forest or potential farmland becomes a source of income for communities, and may include other benefits such as prevention of landslides, soil erosion and water pollution. This income may serve to make up for the loss of income from converting the forest to farmland, while preserving the forest area. Some buyers of carbon credits may require that the carbon stock be increased, whereas others may require only that the baseline of carbon stock is maintained; this aspect must be ascertained when a potential buyer is identified.

In summary:

- A baseline scenario must be defined, along with its potential impact on carbon stocks or other ecosystem services.

- A "with-project" scenario should be developed to outline how the project is likely to affect the ecosystem service and what the additionality will be. This 
can be an increase or improvement in the service (e.g. enhanced carbon stocks) or a reduction in the possible decline of the service.

- A performance-based payment must be made for the change in service. Buyers and sellers must define and agree upon the means of measuring, reporting and verifying the change.

- In some cases, payments may be based on inputs rather than on performance.

\section{Step 8: Collect biophysical data}

The need for additionality or an improvement in the ecosystem service provided, including a shift away from business as usual to an improved situation, is a key principle. To define this change and monitor and report on progress, robust technical data will be required to establish a credible baseline or business-as-usual scenario that considers environmental, social and economic factors.

Biophysical data of appropriate detail and quality must be collected. For each landscape, the technical requirements and skills for data collection will vary depending on the particular ecosystem service provided. For example, data collection and monitoring may involve water sampling, measurement of sedimentation flows or carbon stocks, or analysis of land-use practices.

When developing the baseline, it is important to consider the indicators required by the MRV process. The baseline should consider biophysical, economic and social conditions. Baseline data should be generated for each indicator required for monitoring. In some cases, these should be developed in agreement with the buyer, as in the case of requirements for watershed management or voluntary carbon markets.

In most cases, an appropriately qualified third party, such as a research group or local NGO, could support the data collection and analysis. Parties must determine whether primary evidence is required or if secondary data are sufficient. Ideally, local institutions and villages should be included in data collection and technical support provided. This will further strengthen the involvement and commitment of the local community and relevant institutions in the long-term provision of the ecosystem service. 


\section{E. Credibility, assurance and sustainability: Steps 9 and 10}

\section{Step 9: Set requirements for measuring, reporting and verification (MRV)}

Are systems in place to ensure credibility of the service provision? What MRV will be undertaken to prove additionality?

In PES, MRV serves to prove adequate performance, to justify payments and, ultimately, to maintain the credibility of the scheme. This role becomes even more important when payments are based on performance, as is the case for most PES.

The buyer and seller must agree upon MRV requirements during negotiations, unless the market stipulates MRV requirements, as is the case of carbon stocks.

Communities should be involved in MRV activities, as shown by the ICRAF RUPES program. This program identified four main aspects for ensuring that PES succeeds at the community level:

- participation: communities are included in all aspects, including monitoring

- accountability and verification: data are accurate and can quantify the impact to meet buyer requirements

- prepare the community: communities are aware that financing is not a shortterm project but requires long-term investments and commitment

- intensive facilitation and monitoring.

\section{The role of certification}

Certification of products such as coffee under the Fairtrade system or timber under the Forest Stewardship Council (FSC), for example, entails independent third-party verification of environmental, social and economic conditions in the production and processing of a product. As such, certification provides assurance of additionality for wider environmental services. Certification is a voluntary marketbased mechanism, driven by consumer demand for independent verification and additional criteria. Both buyer and seller/producer incur costs for certification. An example of how certification can be applied to the ecosystem services provided by forests is given in Box 9 . 


\section{Box 9 Certification of ecosystem services: The ForCES project, 2011-2015}

The potential for certification to cover ecosystem services and landscapes is being investigated. For example, FSC, working with partners including CIFOR, WWF, SNV and $A N S A B$, is exploring the potential for FSC to introduce certification of forest ecosystem services. The program, ForCES, is researching, analyzing and field-testing innovative ways of evaluating and rewarding the provision of critical ecosystem services, such as biodiversity conservation, watershed protection, and carbon storage and sequestration.

There are also discussions over the potential use of landscape certification as for certifying PES and associated products, where products from a certified landscape would receive the landscape certificate. Certification and eco-labeling serve as a form of indirect payment for ecosystem payments. ${ }^{11}$

\section{Step 10: Develop pro-poor benefit-sharing mechanisms}

\section{Are fair and equitable means of sharing the benefits in place?}

Ensuring that the financial, environmental and social gains from the provision of an ecosystem service are equitably distributed is a fundamental requirement for sustainability. Equitable sharing of rewards is particularly critical when the service is provided by a community or a collective of individuals. To avoid conflict and ensure all costs of service provision are adequately compensated, a fair and equitable system for sharing the rewards should be developed, to the agreement of all parties (Box 10).

Benefit-sharing mechanisms may vary according to whether the payment is received as cash, as non-cash or in-kind. Where the community provides the service, the payment can take the form of a disbursement of cash to those involved or of funding for a community education or healthcare program or initiative (as shown in the case of Lombok, Box 10). As the Overseas Development Institute (ODI) noted: "Benefits may be more effectively targeted through the provision of community services or employment than through direct financing." 12

All parties must agree on how the benefits will be shared. It is important that the institution selling the service and thus receiving the benefits has clearly established rules for benefit sharing developed in full agreement with all those concerned.

11 Scherr S, White A and Khare A. 2004. For Services Rendered: The Current Status and Future Potential of Markets for Ecosystem Services Provided by Tropical Forests. ITTO Technical Series No. 1. Yokohama, Japan: International Tropical Timber Organization.

12 Luttrell C, Schreckenberg K and Peskett L. 2007. The Implications of Carbon Financing for Pro-Poor Community Forestry. Forestry Briefing Paper 14. London: Forest, Policy and Environment Programme, ODI. 


\section{Box 10. Lombok: A successful PES watershed project}

In 2004, WWF Indonesia initiated a PES scheme for watershed protection in the Rinjani Protected Area, Lombok, Indonesia. The Rinjani landscape covers 125,000 ha of semi-evergreen and tropical rainforest. It is divided into production forest, reserved area and national park, with four districts: Lombok Barat, Lombok Utara, Lombok Timur and Lombok Tengah. A WWF study in 2004 calculated that the economic value of the ecosystem services from this landscape may be has high as IDR 5.178 trillion (USD 575.3 million). The PES scheme was adopted as part of local government policy and a sustainable financing model was set up. This offers incentives for upstream communities to implement good forest management in the Mount Rinjani ecosystem.

The payment mechanism

The local water company involved in this watershed project charges each user an additional fee of between IDR 1000 to more than 2000, with the fee set by user type (e.g. business, individual household, etc.). The income raised is given to an independent body with multi-stakeholder representation, which then oversees the disbursement of funds (approximately IDR 400 million to 500 million per month) to community projects in upstream areas. This body selects projects for funding based on proposals by communities.

It is important to note that the company pays for community projects and does not make individual payments to farmers. This payment is not performance based, so communities will not receive payments for projects depending on a particular activity or change in activity (e.g. reduce sediment by $X \%$ or receive income of $\$ Y$ ).

Source: CoLUPSIA interview with WWF \& ForCES: Indonesia Country Brief.

Payment structures will differ depending on the commodity and the context. Therefore, those designing and implementing a PES system should aim to use existing payment and fiscal structures to avoid duplicating the work.

\section{Adverse impacts on the poor}

It is essential to closely monitor how markets for ecosystem services may affect the poor, as they often have limited property rights and access to finance. Project designers must ensure that the PES scheme meets pro-poor objectives and deals appropriately with gender issues and inequality. Failure to consider these issues can seriously undermine the objectives of PES, as PES schemes are sustainable only if they benefit local communities. ${ }^{13}$

13 Landell-Mills and Porras 2002. 


\section{Sustainability}

\section{Is sustainability of the provision of the ecosystem service assured?}

Are adequate provisions in place to ensure this?

Finally, to ensure sustainability and permanence, all those who are likely to benefit from the PES scheme must be prepared to make a long-term commitment. It is essential to ensure that all those involved are aware of the long-term involvement, including monitoring, accountability and verification, and are have full understanding that financial sustainability requires long-term investment and commitment, with intensive facilitation and monitoring.

Including local communities, the private sector, and if necessary, government officials and NGOs in all aspects of design and implementation is imperative if the PES scheme is to be successful and sustainable. 

This research was carried out as part of the European Union funded Collaborative Land Use Planning and Sustainable Institutional Arrangement project (CoLUPSIA). Run by CIRAD in partnership with CIFOR, TELAPAK and several local NGOs and universities, the project aims to contribute to avoided environmental degradation and to strengthen land tenure and community right by collaboratively integrating all stakeholders' views in land use planning processes. The outputs revolve around the relationship between land use planning, land allocation and the provision and potential payment of ecosystem services. The project focuses on two regencies (kabupaten), Kapuas Hulu and Central Maluku in Indonesia.

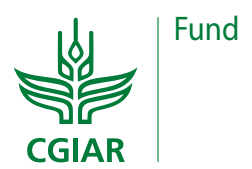

CGIAR
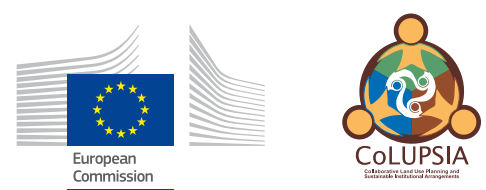

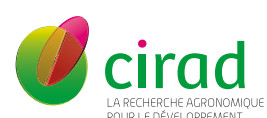

Center for International Forestry Research (CIFOR)

CIFOR advances human well-being, environmental conservation and equity by conducting research to help shape policies and practices that affect forests in developing countries. CIFOR is a member of the CGIARConsortium. Our headquarters are in Bogor, Indonesia, with offices in Asia, Africa and Latin America.

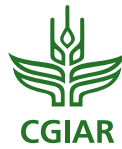

